Página inicial: 271 - Página final: 287

TIPO DE ARTÍCULO: de Reflexión

\title{
RECONCILIACION Y RESPONSABILIDAD: ACCIONES DE SINERGIA PARA LA CONSTRUCCIÓN DE UN PENSAMIENTO ECOLOGIZANTE DESDE LA ESCUELA. "INCERTIDUMBRES SEMILLA."
}

\author{
RECONCILIATION AND RESPONSIBILITY: ACTIONS OF SYNERGY FOR THE CONSTRUCTION \\ OF A GREEN THOUGHT FROM SCHOOL. \\ "UNCERTAINTY SEED."
}

Recibido: Junio 2014 Revisado: Septiembre 2014 Aceptado: Octubre 30 de 2014

Por: José Alonso Andrade Salazar ${ }^{1}$.

\section{RESUMEN:}

Esta artículo, derivado de las discusiones fruto de varias investigaciones realizadas, tiene como objetivo proponer una acción de ruptura respecto a la dinámica devastadora de la humanidad ante los recursos ambientales y ecosistemas, para lo cual se propone la generación de "incertidumbres semilla" que actúan a modo de acciones pedagógicas de cambio instauradas desde la infancia como registros de acción, retroacción e interretroacción pedagógica-social. Para ello se plantea que la responsabilidad medioambiental y la reconciliación de la humanidad con los ecosistemas, emergen como constructos dialógicos de sentido ecologizante, por lo que deben ser apuntalados en el proceso educativo y (de)construidos en quienes alteran la organización de los sistemas vivos.

\section{PALABRAS CLAVE:}

Complejidad, incertidumbre, incertidumbres semilla, pensamiento ecologizante.

\section{ABSTRACT:}

This article, derived from the product of several investigations carried out discussions, aims to propose an action of rupture on the devastating dynamics of humanity to environmental resources and ecosystems, which proposes the generation of "uncertainty seeds" that act as a pedagogical actions of change, installed from childhood as records of pedagogical and social action, feedback and inter-feedback. This raises the environmental liability and the reconciliation of humanity with the ecosystems, to emerge as dialogic constructs of greening sense, so that it must be underpinned in the educational process and (de) built on those who disrupt the organization of living systems.

\section{KEY WORDS:}

Complexity, Uncertainty, Uncertainty Seed, and Greening Thought.

\footnotetext{
${ }^{1}$ Psicólogo clínico. Mg. Pensamiento Complejo. Doctorado en pensamiento complejo. (Mexico). Docente ivestigador y coordinador de investigación Universidad de San Buenaventura Medellin, extensión Armenia. Armenia, Colombia. Contacto: jose.andrade@usbmed.edu.co.
} 


\section{Introducción.}

Diversas expresiones de alarma ante la explotación indiscriminada de la naturaleza emergen a la segunda mitad del siglo XX, dichas voces reiteradas por los diversos estamentos entre ellos "El club de Roma" en 1972 dan a conocer a través del informe de "Los limites del crecimiento" datos acerca de las consecuencias del mantenimiento del consumo desbordado antes del año 2100 los cuales conducirian a la humanidad a vivir un desastre irreversible (Delgado, et al., 2005). Sus tonos apocalipticos o la interpretación aterradora y fatalista de los hallazgos desatan divergencias, posiciones a favor y en contra, ambivalencias e incluso resistencias para incorporar las posibles y necesarias acciones conjuntas de cambio respecto a la actividad extintiva del hombre sobre el mundo, especialmente cuando las sociedades del consumo estructuraban su principio de realidad con base a un falso ideal de bienestar construido sobre el presupuesto de dominio de la naturaleza, el consumo de los bienes que el mundo otorga y la adquisición de una materialidad general sobre la cual se busca el bien común y el bienestar social. La preocupación en realidad afirma Edgar Morín (2002) no era la alerta energética o la búsqueda romántica de un equilibrio en la naturaleza, sino el reconocimiento y comprensión de una realidad innegable: la necesidad de una toma de conciencia ecológica que reúna lo escindido entre ciencia, tecnología y desarrollo moral.

"Desde 1956 el consumo se han multiplicado por cuatro, en los últimos 50 años el consumo de combustibles fósiles se ha multiplicado por cinco, las capturas marinas se han cuadruplicado, el consumo de madera y agua se ha duplicado, mientras que las emisiones de desecho se han triplicado en los países industrializados" (Lumelsky N. y cols. (2001). Informe club de Roma, 2001, citado por Chavez, (2005) en Delgado el at, 2005)

De acuerdo a estos elementos la preocupación científica y ciudadana en relación a su nivel de participación familiar-social-comunitaria-global en esta devastación, además de la inserción de los resultados científico-tecnológicos en la vida socialcomunitaria y en la naturaleza, ha promovido el surgimiento de un pensamiento Bioético -no reductible a compartimentos intelectuales- que forma parte del sentido común y la vida politica, al tiempo que cuestiona la ciencia y lo científico acoplando sus avances pero con una posición crítica acerca de las finalidades y medios empleados en la adquisición del saber. Dicho así "el surgimiento de la Bioética está vinculado estrechamente al avance científico-técnico alcanzado por la sociedad contemporánea en la segunda mitad del siglo XX" (Delgado, 2005, p. 6) una sociedad que avanza en pos de revoluciones cientifico-técnicas (RTC) pero que comienza a dudar de su efectividad como "único saber o conocimiento absoluto" al ver en los actos de beligerancia y de maldad gran parte de las consecuencias de integrar a su vida cotidiana una tecno-ciencia sin regulaciones ni arbitrajes a su labor. En general "los procesos de acercamiento entre la investigación científica, el sistema productivo y la vida cotidiana se profundizaron en la segunda mitad del siglo, formando parte del proceso conocido como Revolución científico-técnica" (p. 7) en la que el desarrollo moral creció en los anaqueles filosóficos integrándose totalmente solo cuando los desastres naturales cobraron consecuencias irreversibles para los ecosistemas que garantizan la vida y habitabilidad del planeta.

Referencia de esto son los diez peores desastres que la revista TIME publica en su edición de 2010. Entre estos se encuentran el desastre Chernovil (explosión de la 
planta nuclear en Ucrania en 1986), la fuga de agentes tóxicos de una planta de pesticidas en Bhopal-India que dejo 15 mil muertos, la orden de Saddam Hussein en 1991 de explotar los pozos petrolíferos en Kuwait (los cuales ardieron por 7 meses), la emergencia de desechos Tóxicos enterrados en el pueblo de Love Canal (21 mil toneladas), el derramamiento de 11 millones de galones de crudo en 1989 (barco Exxon Valdez que encalló en Alaska), la crisis nuclear actual en el Japón, que comienza en 1999 con el desastre de la planta Tokiamura, cabe mencionar que este país cuenta con 55 reactores nucleares. A esta crisis nuclear debe sumarse la crisis de la planta nuclear de Kashiwazaki-Karigua (2007) en la que se presume se arrojaron miles de litros de agua radiactiva al mar, y la explosión de la planta Fukushima en el 2011. Otros desastres fueron la nube dioxina TCDD de SevesoItalia en 1976 producto de una explosión de una planta química; el "Mal de Minamata" que sufren los habitantes del pueblo Minamata desde 1956 como efecto del consumo de productos de mar en Japón (las aguas estaban contaminadas por desechos radiactivos), y el Three Mile Island connotado como el peor desastre nuclear de los estados unidos en 1979. A esto deben aunarse en Latinoamérica los peligros contaminantes de la planta nuclear Usina Angra II de Brasil que según ambientalistas desde el año 2009 emana radiaciones al medio ambiente.

De acuerdo con Delgado (2005) los constantes procesos de avance científico tecnológico traen consigo el germen de una subversión de la vida comunitaria en el sentido espiritual, el cual es visible a través de la destrucción de las costumbres y solidaridades, por lo que el ethos cientificista se transforma en el único medio o modo ideológico de realización vital, ergo sucede una especie de inversión valorativa que conduce a un empobrecimiento mayor de la relaciones entre seres humanos y de estos con el resto de las especies, lo cual es garante de exclusión, ilegitimidad y marginación del otro. A este hombre "homo demens" que pertenece al común pero que se desarrolla en entorno bio-tecnologizado se le deben brindar las herramientas de cuidado del medio ambiente y de relación co-cuidadora con el ecosistema desde edades cada vez más tempranas ya que requiere de "una atención especial, pues su conversión en un agente positivo se considera posible a través del proceso de educación ambiental" (p. 26). Los cambios en el siglo XX se relacionan con la tecnología y el conocimiento científico pero no están supeditados únicamente a sus interacciones, existen mecanismos de activación que parten de escenarios tradicionales de relación o reunión constante del hombre con la naturaleza, mecanismos no-disyuntivos anclados a la tradición y el encuentro social, en este sentido,

"La activación de las personas comunes en la sociedad contemporánea no puede explicarse solamente como resultado de los procesos de educación y las facilidades tecnológicas para la comunicación social; tiene que ver ante todo, con la construcción de nuevos espacios y modos espirituales de realización de la propia vida cotidiana, que los han forjado como sujetos nuevos de una cotidianeidad transformada" (p. 13)

\section{Titanic planetario y pensamiento ecologizante.}

De acuerdo con Morín (1995; 2003) la humanidad convive en una especie de Titanic planetario que en su borrosidad implícita torna explicitas los sentidos con los que entiende -pero no comprende- las acciones direccionadas a la conservación y reproductibilidad del pensamiento ecologizante (Morin, 1996a); dicha metáfora del Titanic se soporta sobre la idea de que el planeta es un barco que puede hundirse 
en cualquier momento y ello implica en un sentido extremo la extinción de la especie humana. Así el mundo se mueve por un cuatrimotor planetario [económico, científico, tecnológico e industrial] que consume, vende, compra, oferta, demanda, regula, controla y experimenta sobre la vida y los destinos de lo vivo, el cual al ser impulsado sin control ético y politico produce daños irreversibles a los ecosistemas, aunque también genera una posibilidad de cambio en las hélices mudializantes que orientan los destinos de su acción teleológica y depredadora de los sistemas vivos. Según Morín (1984; 2003) las mundializaciones han determinado las racionalidades con las cuales el ser da cuenta de su relación de dominio de su entorno más que de una integración con el universo y con otras especies, todo ello bajo el principio rector del control-inspección y la racionalidad-explicación de los fenómenos naturales desde un escenario concreto de experimentación reduccionista. La idea de control "social, natal, mental, político, pedagógico, clínico, etc.," parte de un principio reductor, es decir de una tendencia no-Hologramática que ha impulsado al ser humano a buscar "afuera" lo que debe generar, activar, recrear e interrelacionar en su conciencia individual y colectiva. En este sentido las explicaciones acerca de lo que sucede con el planeta están dadas por un logos cientificista cuyo motor de trasformación constituye leyes, registra cambios, divide relaciones, reduce componentes y delimita las acciones creativas, subyugando la incertidumbre, buscando la estabilidad, la homeostasis perpetua y la alienación sucesiva de los sujetos y los sistemas sociales.

Esta idea implica además, que aunque se tenga conciencia del daño ambientad, la imposibilidad de generar un cambio global complejiza la transformación de la relación de la especie humana con la naturaleza. Aún no sabemos si estamos en la barrera próxima a la crisis general del sistema planetario-ecológico, o si la pasamos o si estamos en ella. El Titanic navega pero puede chocar y encallar con una certeza: la noción de que depredamos el mundo y ya no tenemos nada para el porvenir, quedando de esto es la artificialeza, lo transgénico y relaciones transgénicas, interacciones virtuales alejadas de lo vivo y del contacto con lo vivo. Por todo esto se requiere otra cosmovisión que la que se genere una nueva posibilidad de inclusión de lo excluido, que recupere lo ancestral y retome el asombro y las solidaridades entre especies.

Lo propuesto frente a esto no es cambiar el motor, sino como diría Morín (1996) establecer regulaciones a los motores y sus hélices impulsantes, a través de una actitud transformadora de cambio "que reforme las reformas", pues si en un principio el desarrollo humano estuvo mediatizado por los diversos tipos de "mundialización" (1- Colonizadora: "descubrimiento de América, y 2- Homogenizante-espiritual: San Bartolomé de las casas, Montaigne, humanismo), el desarrollo actual también está impulsado por nuevos motores [técnico-científicos-económico-industrializados] cuyas concepciones del hombre y la comunidad buscan la heterogeneidad y la enunciación de leyes generales, como también de la simplicidad argumentativa de la complejidad del ser, las redes y los sistemas sociales. Dicho así, esta tendencia a la depredación y consumo a ultranza en las sociedades actuales también bosqueja la eventualidad de un cambio en el sentido que la Globalización le da a lo diverso y a la vida. La globalización actual involucra el uso de la NTICS (nuevas 
tecnologías de la información y de la comunicación) como también de los sistemas de comunicación familiar, intersubjetivo, intercomunitario, etc., además de la contextualización noosférica de los saberes, sentidos, proposiciones y posiciones respecto a los fenómenos, regulaciones, ethos- auto-Oikos y las categorías biofísicas y socioculturales. En este campo de acción no puede existir una globalización excluida de lo espiritual, metafísico, de lo inefable y social-comunitario, de la doxa y la reunión colectiva, de lo tradicional y arcaico.

La metáfora del cuatrimotor indica que las hélices mueven al planeta hacia la destrucción, así Morín (2003) propone abandonar la metáfora de las hélices de tipo económico, científico, tecnológico e industrial y asume la metáfora de una "doble hélice" que parte del antagonismo entre una hélice marcada por la dominación o primera mundialización (Conquista, colonización y esclavitud del "nuevo mundo"), y la segunda mundialización enfocada en el ser, su personalidad-individualidad, los valores humanos, los derechos universales, la democracia y la descolonización entre otros aspectos, es decir en la conciencia y sentido de conformación de la comunidad de destino continental-planetaria cuyo motor principal es la responsabilidad y la solidaridad. Si bien la humanidad no renunciará del todo a estas hélices es posible que estas se muevan por motores bioéticos y politicos que posibiliten mejores regulaciones a una ciencia que se estructura con poca conciencia de lo humano y de la afectación que tiene en los ecosistemas.

Siguiendo a Habermas $(1985 ; 1989)$ es posible considerar la modernidad a partir de un proceso en marcha que no se reduce a los descubrimientos científicos; en este sentido la modernidad no somete la condición de "adelanto" a atributos por fuera de la bioética y la cultura ya que ambos elementos se pueden pensar como contribuyentes necesarios para el desarrollo de una globalización culturalcompleja, mundialización que requiere de un componente ecologizante de base (auto sostenible, perdurable, ecológico, protegible, etc.). Este concepto no solo incluye lo externo al sujeto como entidad sino el hecho de asumir al ser como una de las posibilidades de existencia presente en la naturaleza de lo vivo, condición que invita a comprender su operatividad recursiva acorde a procesos de transformación sociocultural, ya que instaura a partir de la evolución de la especie humana acciones de responsabilidad y reconciliación derivados de sus prácticas comunitarias, y de la interrelación bioética con otras especies y el cosmos. Dicho esto el pensamiento complejo está planteado como un anti-método o estrategia de pensamiento que enfrenta la complejidad e incluye rupturas con el paradigma de la simplificación, con base en el avance y la reforma en el conocimiento y en las practicas humanas en cuanto re-organización dialógica de las relaciones vinculares: orden, desorden, caos y organización, aspectos claramente aplicables a la comprensión de la complejidad de los sistemas sociales (Romero, 2003). La auto-responsabilidad y la auto-reconciliación con el ecosistema son dos acciones de re-integración sistémica que presentan e incluyen sus opuestos admisibles en el comportamiento antiecologizante (irresponsabilidad y anulación sempiterna) constituyéndose en el autos y el oikos de una relación ecológica-empática con el medio ambiente. Al respecto Potter (1998) expresa: 
"De acuerdo a mi punto de vista la Bioética, como una ciencia para la supervivencia humana, tiene que establecer puentes para las ideas éticas sociales ya existentes y orientaciones anticipadas. Este principio debe ser introducido a los individuos a una edad temprana. La Bioética Puente no encuentra un terminal ético sólido al otro lado del puente hacia las humanidades. La era de especialización ha tomado el control: la Ética se ha transformado en una materia de Ética Aplicada.” (p. 27)

\section{Responsabilidad, reconciliación e incertidumbres semilla.}

Las nociones de responsabilidad y reconciliación son guias orientadoras que se inscriben transversalmente en las dos hélices propuestas por Morin para replantear el desarrollo humano-ecológico desde un punto de vista sostenible, las cuales son las regulaciones éticas y políticas-económicas (Morín, 2003). De acuerdo a lo expuesto los cambios "posibles y necesarios" no se basan solamente en la "buena voluntad" de algunas personas e instituciones ecologistas, sino en la decisión de implementar de manera conjunta meta-macro-acciones transformadoras a nivel global, lo que requiere la ejecución de una pedagogia de tipo critica, ambiental, compleja, ecologizante y los aportes a dicha propuesta del holismo ambientalista (Morín, 2003; 2007). Como propuesta de reforma se plantea que la generación de "incertidumbres semilla" en los niños y niñas amplian su rango de comprensión y el deseo de saber y relacionarse con el mundo. Cabe mencionar que la incertidumbre emerge de forma natural en los niños y niñas y el asombro ante lo descubierto y lo creado es uno de sus indicadores, en consecuencia la curiosidad y creatividad naturales de todos los seres humanos no debe comprenderse como uno de los modos de apropiación del mundo y de la naturaleza o a modo de intento de dominación natural, sino como pseudo-ordenamientos de la experiencia y subversiones ante la objetividad disyuntiva adulta, emergentes a partir de dominios complejos de emoción y de acción cuya constante relación dialógica "digitoanalógicas-consensual" con la naturaleza (el otro, el Otro, lo otro, lo imposible pensado, la phisis, lo inefable, etc.) permite el establecimiento de una correspondencia incesante de intercambio con otros sistemas vivos.

Respecto a la propuesta de "Incertidumbre semilla" se debe anotar que como tal designa una posibilidad de ruptura del modo como se aprende a aprehender la realidad y sus emergencias, lo anterior quiere decir que emerge a modo de estrategia de transformación de la forma como el ser se aprehende a sí mismo, incluyendo los estados y variaciones percibidas, sentidas y auto referidas, la variedad conductual propia de la vivencia entre las especies, los diversos estados y posiciones de las cosas que componen el mundo, los conceptos, imagos-imaginarios y representaciones cosmovisivas que definen el estado de humanidad y de especie, como también de todas aquellas condiciones, momentos y resultados de la complejidad asociativa en las emergencias de la acción fenoménica de los sistemas que sirven de material experiencial en el aprendizaje significativo y la conformación de una identidad terrenal en el marco de la autonomía sociocultural. La "Incertidumbre semilla" es en realidad una acción de auto-preservación que busca evitar la post-depredación de los sistemas vivos por mano humana constituyéndose en un ejercicio de ruptura que aspira desde la infancia a construir un saber unificado de civilidad, eticidad y humanización que eleve la autoconsciencia respecto al lugar y la 
responsabilidad del ser en el cosmos (Romero, et al, 2003), y transforme la existencia de un "homo demens" cuya ceguera generalizada ha instaurado un autismo civilizatorio y la compartimentalización de afectos, especialidades y experiencias por separado, aspecto que centra-posibilita-reactualiza el conocimiento científico pero que da la espalda a la realidad sociocultural del hombre. Al respecto Humberto Maturana propone,

"Todo quehacer humano se realiza en conversaciones, en redes de coordinaciones de acciones y emociones que resultan de un fluir entrelazado del hacer y el emocionar en el lenguaje, y toda acción queda definida como tal por la dinámica emocional que sustenta los procesos que la constituyen en el dominio del hacer" (Maturana, 2002, p. 226)

Para los infantes la "responsabilidad" es un concepto abstracto que solo se puede aprender a través del ejemplo, por ello los elementos, prácticas y acciones son fruto de aprendizajes significativos y socioculturalmente útiles emanados de una relación dialógica con el mundo adulto y sus procesos de socialización. Desde el punto de vista moral esto puede determinarse como un valor, aunque para el caso del pensamiento ecologizante va más allá al convertirse en una inscripción, una huella constante, es decir en una experiencia o instrucción acerca de la elección de conservar, respetar y restaurar el medio ambiente. Lo anterior es constitutivo de acciones que dan sentido a la experiencia de cuidado global-ecológico del mundo, del ser humano, la vida y las especies. En este aspecto la idea de trabajar intercontinentalmente en el apuntalamiento del holismo ambientalista se puede establecer a través de una idea ecologizante semilla desde los primeros años de vida humana, transformándose luego en un evento y una ficción posible que requiere acciones conjuntas que la hagan viable, especialmente si se comprende que en gran medida las estructuras de saqueo de los recursos naturales se encuentran montadas sobre andamiajes de poder y regulaciones heteronómicas, las cuales funcionan porque de forma autopoiética se reproducen a sí mismas a través de procesos de socialización inscritos a sus ordenamientos y dominios socio-ideológicos. En relación a lo expuesto el pensamiento ecologizante convoca una ruptura potencial del sistema represivo que libere e instituya en los sujetos (de cogito y de computo) la idea de que se convive con otras especies bajo dominios de diversas comprensiones de dichas relaciones (Morín, 1996a), así cada especie tiene su propio proceso, sus emergencias y sistemas particulares de cambio y auto reproducción.

La propuesta "de reconciliación" emerge para todos y con todo, porque la humanidad requiere un acto de encuentro consigo misma y con su naturaleza, que traspase la dialéctica-represiva de los sistemas pedagógicos tradicionales e instaure el principio dialógico como punto de partida para el conocerse a sí misma, al otro, lo otro y a los otros. No se trata de generar una culpa por lo que se hizo o instaurar como necesario acciones de hecho implementadas por la fuerza, la coacción o la violencia. La reconciliación requiere un trabajo de transformación que incluya lo no-incluido hasta ahora en la comprensión del mundo, las cosmogonías antiguas y nuevas, los pensamientos y acciones tradicionales y sus operaciones dialógicas, las emociones y conductas como también, un sistema de regulaciones y controles intercontinentales que minimicen el impacto ambiental producido por 
las hegemonías económicas e industriales. La propuesta busca cooperar en la regulación de los estados de consumo masivo a fin de concebir un mejor estado global de conciencia ambiental. Se trata de una idea sembrada desde la infancia en el sistema de enseñanza-aprendizaje que trabaje con y para el desarrollo de mejores ecologías mentales dialógicas-complejas y evite la enunciación totalizante de economías político-pedagógicas orientadas a la depredación de los recursos naturales (Morín, 1999), que buscan la reproducción artificial de los dominios de la naturaleza en campos de concentración experimental, que a su vez subvierten la vida y los valores al aumentar el adormilamiento o no-empoderamiento socialcomunitario, colectivo-familiar e individual respecto a la responsabilidad y la necesidad de reconciliación con el medio ambiente. Al respecto de la reconciliación Jacques Derrida opina:

"La palabra "de reconciliación" es el acto... por medio de una palabra nos antecedemos, entablamos la reconciliación dirigiéndonos a otros, se ofrece por la palabra, es decir por un término, ... toda herida imaginable no atañe a un tejido viviente sino dejando en ese momento una cicatriz, por ello el perdón y la reconciliación no tienen sentido sino alli, en donde se producen, el cual es el escenario de la memoria, donde la herida dejó o pudo dejar un recuerdo, una huella, una cicatriz para curar o para aliviar, para pensar. Hablar es comenzar a reconciliarse, aun cuando nos declaramos la guerra, esa es una reconciliación en marcha" (Derrida, 1999)

Es necesario afirmar que los niños y niñas no necesitan esta reconciliación ya que son los adultos, adolescentes y jóvenes quienes requieren de manera urgente transformar sus ecologias mentales (Bateson, 1999), es decir sus acciones, reacciones, creencias, paradigmas y su identidad planetaria, resignificando aquella relación reduccionista entre causa-efecto, misma que agota sus respuestas en la descripción jerarquizada de causas y leyes, al tiempo que reproduce acciones paliativas de cambio ambiental ante las consecuencias nefastas de la depredación humana respecto al medio ambiente. Por consiguiente el cambio debe darse en relación a una reacción en espiral o "bucle" activo, retroactivo e inter-retro-activo (Morín, 2003) donde cada acción es al tiempo causa y consecuencia de un sinnúmero de posibilidades de acciones en relación a la restauración y permanencia de los sistemas ecológicos y del pensamiento ecologizante. Se puede afirmar que los niños y niñas contrariamente a lo que piensan los adultos respecto al vivir en este planeta, al no estar contaminados del estigma del consumo, el acomodamiento perceptivo, la pereza ecológica y la no-acción ante la destrucción de los ecosistemas, viven y existen en la conciliación, sin embargo muchos modelos pedagógicos limitan dicha acción de sentido ecológico al consumo de saberes y no a su creación constructiva. Así gran parte de la humanidad y sus regimenes prescriben como actividad necesaria para el desarrollo la inserción de sujetos-productivos-consumidores que a la postre son consumidos por el sistema del cuatrimotor y sus hélices globalizantes (Morín, 1984; 1996).

Los niños y niñas son seres ecologizantes porque en un inicio su existencia no se limita o restringe por los cánones, leyes y disyunciones del mundo adulto y aun con 
un proceso de socialización y adquisición de lenguaje conservan gran parte de su creatividad y asombro, por ello es posible plantar en sus ecologias experienciales mejores modos de relacionarse consigo mismos, con el planeta y el cosmos, lo cual constituye una responsabilidad ética y también un acto de reconciliación del adulto con el mundo que paulatinamente destruye. La idea de la "incertidumbre semilla" parte del concepto de transformación pedagógica e invita a la sociedad a realizar una innovación didáctica y social que apunte a la modificación de las actuales ecologias sociales y mentales a fin de que se ajusten a los nuevos dominios y complejidades del saber comprensivo acerca de lo vivo. Esta experiencia de sentido es dable en términos de existencia auto-ecologizante e incluye el reconocimiento de la diversidad de dominios de lo vivo y su tendencia a la acción, retroacción e interretroacción creadora. Las acciones e intenciones de cambio en este campo de actuación implican modificaciones sustanciales a los modos como se aprende a aprehender lo natural, la naturaleza y la interacción entre sistemas vivos, aspecto que parte de un acto de conciencia global en el acontecimiento emergente, y de la reunión de rupturas y explicaciones históricamente divergentes acerca del hombre y su existencia biopsicosocial (pensamiento, acciones, ideas, posiciones, disyunciones, variaciones, reuniones).

El ser humano requiere de manera urgente reconciliarse consigo mismo y con el entorno inmediato, aspecto que en maestros, padres de familia y en la comunidad parte de la intención (de)constructiva de su condición de humanidad, como también de la interacción con el medio ambiente y el cosmos. Por tanto lo anterior evita la división por compartimentos de los "estados o momentos de la reconciliación" a nivel comunitario, familiar, política, ideológica, social y religiosa, se trataria de una reconciliación antropoética y global. La conciliación es un acto de acuerdo mutuo, al tiempo que la reconciliación es un re-acuerdo con aquello escindido del ser mismo "su naturaleza", siendo una acción trascendente que puede tener diferentes vías y demostraciones. Una de estas vías es el nucleo conformado por la expansión del perdón, la toma de conciencia, y el paso a la acción transformadora. Cabe mencionar que en los niños y niñas es posible incubar y reforzar una incertidumbre semilla o deseo elevado e inagotable de dialogar con la naturaleza y su creatividad, es decir de transformarse en el acto de encuentro con su acontecer "emergencias, creaciones, fluctuaciones, derivaciones, caos, etc.", de asombrarse de sus mutaciones y ser parte de ellas. Se trata grosso modo de una incertidumbre Bioética que dialogue y (de)construya la marginalidad pedagógica derivada del enciclopedismo, por tanto que torne apetecible el hecho de superar la inversión de valores (antivalores) y facilite la emergencia de acciones y cuestionamientos bioéticos ante el empobrecimiento de la diversidad y la estandarización de la vida humana (Delgado, 2005). Esta didáctica ecologizante propende por reunir, incluir, conservar, e interrelacionar las especies y ecosistemas, lo cual aumenta en el educando la tendencia a la sociodiversidad, la autonomía ambientalista, la sintalidad (identidad) biológica y la cohesión grupal ecologista, aspectos que suscitan acciones hacia el cuidado mancomunado de los ecosistemas.

En los adultos las experiencias de reconciliación pueden fomentar la necesidad de transformar en sí mismos y en otros el estado de subversión material de la vida cotidiana, condición que en gran medida lo induce a no cuidar de la naturaleza sin 
destruir las diversas formas de vida. Lo anterior en los educadores (familia, docentes y comunidad) tiene que ver con el tema de la responsabilidad global frente a una educación ecologizante y transformadora, que convoque la conformación de un estado biopsicosocial-transcultural, que se decante a sí mismo en diversas posturas, posiciones y opiniones acerca de lo vivo, tomando en cuenta la no-reducción, la inclusión y el análisis sistémico de los sistemas vivos. La incertidumbre semilla es en sí misma una tendencia a la acción que evoca lo aprendido y la experiencia (retroacción), llegando a observarse y reproducirse (interretroacción) de forma autoecologizante en quehaceres locales que apunten a construir un mundo perdurable, sostenible y diverso (Mayor, 1999), un mundo en el que todos participen de la restauración planetaria, lo cual ya es en sí mismo un acto de responsabilidad pedagógica, al tiempo que una acción de reconciliación humana con las especies, el mundo y el universo.

La existencia humana confronta a los seres de forma constante a dilemas (disyunciones, divisiones, maniqueísmos, etc.) que a modo de propuestas de cambio operan en diversos dominios de acción-cognición-emoción. Estos elementos a menudo son reducidos analíticamente a lineamientos y cartografias experimentales, a estereotipos de reacciones que pueden resultar inoperantes para los nuevos dominios de interacción que los sucesos biofísicos y socioculturales proponen. Dichos escenarios a la vez retos y posibilidades de transformación socio-pedagógicos de las interrelaciones, al tiempo que oportunidades de acoplamientos de las "emergencias" propias de la no-linealidad de la vida cotidiana. Las emergencias surgen del indeterminismo de la vivencia y se reestructuran en la dinámica del lenguaje y el encuentro, de acuerdo a complejos mecanismos de asunción y reintegración auto-transformadora de procesos, posiciones, roles, afectos y emociones entre otros aspectos. En este aspecto existe una compleja red de relaciones que da sentido a los procesos de auto-organización, ya que incluso en el desorden aparente de un acontecimiento "caótico" como sucede en las catástrofes naturales o artificiales, las tramas de eventos se contextualizan, transsolapan y acoplan estructural e indefinidamente.

Como consecuencia cuesta trabajo articular el conflicto con el desorden aparente de los eventos naturales, sociales o personales, pues muchos sucesos incontrolables son interdependientes de la cogitación humana, es más su compleja computación es relevante y acorde a su condición autopoiética o circularidad de sus procesos de causación (Colectivo docente internacional [CDI], 2012). En realidad la dificultad de la reorganización biopsicosocial ante problemas ecológicos, emerge cuando la capacidad integrativa de los sistemas sociales, emocionales y cognoscitivos reduce la solución del conflicto a la división y el análisis fraccionado de los fenómenos, aspecto muy ligado al entendimiento de un suceso más que a su comprensión dialógica. Cabe acotar que en estos sucesos se requiere de la toma de decisiones puntuales que involucran los ordenamientos politicos y legales, sin embargo la dificultad real se centra en el hecho de que la globalidad de sistemas debe asumir a priori que la necesidad de cambio no es un problema sino una obligaciónoportunidad inevitable, por lo que su emergencia no es un obstáculo que impida alcanzar un objetivo o realizar una acción ecológica. 
Pese a los tropiezos locales y transnacionales para generar una conciencia ecológica global es posible afirmar que existe en la humanidad una "incertidumbre semilla" que propenda por la orientación dinámica hacia el cuidado del medio ambiente, lo cual implica el desarrollo de una efectiva plasticidad yoica (Fiorini, 1987) que en gran medida logre ajustarse a diversos contextos o dominios de interacción de lo vivo, que promueva mejoras re-formas educativas respecto a lo ambiental y logre resignificar las reacciones restrictivas-limitantes de los motores de desarrollo, produciendo aprendizajes adicionales y operaciones revolucionarias, creativas y reorganizacionales de las acciones de auto-causación determinadas por el bucle de "inter-retro-acciones" entre los ecosistemas. Para algunos adultos la inclusión de cambios efectivos en su relación con el ecosistema tiene un tiempo prolongado a razón de que su proceso de acomodo y reorganización es pausado o se encuentra limitado por esquemas, modelados, prejuicios, hábitos, o por distorsiones cognitivas con las que han aprendido a entender y clasificar jerárquicamente los eventos vitales. Esto sucede especialmente cuando personas y comunidades se encuentran acondicionados a vivir una realidad a través de determinismos conductuales y emocionales que afectan la capacidad emergente-creativa del sujeto para desenvolverse en su entorno (Bleger, 1974).

\section{Educación en valores ecológicos.}

La educación en valores con un enfoque ecologista desde la infancia conlleva reestructuraciones y modos de auto-transformase en el Oikos y el Locus comunitario, por ello "la regulación moral de la vida social también consiste en enfrentar nuevas situaciones mediante el ejercicio educativo que permita a la comunidad humana crecerse ante ellas" (CDI, 2012b). Dicho esto es posible afirmar que en los sujetos adultos a diferencia de los niños y niñas los problemas para aprehender la convivencia ente las especies a partir de las incertidumbres morales, tiene en un primer momento una naturaleza complicada más que una condición compleja, todo ello debido a la borrosidad de los marcos de referencia del "deber ser moral" que condicionan su actividad recursiva y sus deseos de cambio, por este motivo la complejidad de lo moral se transforma en un acontecimiento producto de lo emergente cuando cada persona y comunidad logra ir más allá del suceso y no estanca su experiencia en conceptos y explicaciones sesgadas, es decir en el momento en que sus acciones de reparación de los ecosistemas están "en, a través y más allá" de la culpa, la obligatoriedad jurídica de reparación, la categorización y la explicación objetivista.

A nivel pedagógico existe de forma cada vez más global una reflexión acerca del papel definitivo del sujeto-bioético en su propio desarrollo y la interinfluencia constante y dinámica-conjunta de los contextos biofísico-socioculturales en los que se desarrollan las habilidades de aprendizaje, consensualidad, resiliencia y cuidado del medio ambiente, además de las condiciones sinérgicas requeridas para comprender y transformar el mundo presente, integrando las fluctuaciones derivadas de las diversidades del pensar lo ecológico y siendo conscientes de la multiplicidad, diversidad y propiedades emergentes de los sistemas naturales y artificiales (Romero, 2003). Grosso modo la falta de "Meta puntos de vista" (Morín, 
1988) acerca de la crisis ecológica y la tendencia a reaccionar de forma análoga ante lo "esperado" de forma apocaliptica respecto al destino negativo de los ecosistemas, genera acostumbramientos comportamentales cuya enunciación es evidencia del elevado grado de adoctrinamiento de las ideologías dominantes respecto al papel de la humanidad en la conservación del medio ambiente, como también de la inercia unidimensional de las comunidades para transformar las ecologias mentales, aspecto que permite la evitación y anulación de los fenómenos biofísicos y sociales relacionados con la prevención de los daños a los ecosistemas, además de alteraciones a la individualidad y multiplicidad de acciones, retroacciones e identidades constituyentes en el plano de la conciencia ecológica (CDI, 2012).

Cabe anotar que en el caso de los desastres ecológicos como también de las acciones anti ecologistas de la cotidianidad tales como arrojar basura a la calle, caza indiscriminada, baja conciencia del reciclaje, tala de árboles para adornar las ciudades o el desorden en el manejo de las basuras entre otros, la conciencia ecológica opera bajo los efectos de la huella moral propia de los valores adscritos a las pautas de crianza ecologizante, asi las experiencias de crianza pueden constituir aprendizajes ambivalentes positivos / negativos que refuercen la conducta anti-ecologista a posteriori, o por el contrario determinen el curso de acciones individuales y colectivas de reparación medioambiental. La actividad antiecológica es una postura destructiva que rompe con el ciclo natural de los ecosistemas, y se constituye en cierta forma de caos que promueve la reorganización/regulación bioética y política de las sociedades, por ello desde una posición dialógica la transgresión de la norma no subsiste sin el intento de subvertir lo normativo, así la crisis es siempre una posibilidad de reunir, unificar y recordar que lo uno (el deseo de cambio) no es sin lo otro (las acciones de cambio), y que lo uno (la reparación) es al mismo tiempo lo otro (la intención). Las incertidumbres semilla como acciones de conciliación y reconciliación buscan que la conciencia ecológica como totalidad aprehendida no sea abstracta ni vacía, pero si integral e integrativa, organizativa y re-organizacional, procesual pero no reductible al proceso. Lo anterior invita a comprender que la contextualización de los fenómenos sociales y la actualización incesante de la relación "observador-actor social y fenómeno social" implica que toda acción colectiva sea auto-eco-organizativa de los sistemas tanto como de las comprensiones acerca de lo que sucede en los ecosistemas (acontecimiento, solidaridades, defensas, estrategias, etc.).

\section{Conclusiones.}

La complejidad del pensamiento ecologizante existe en, a través y más allá de su inestabilidad-estable y en su estabilidad-inestable (CDI, 2012) e incluye el orden, el desorden, el azar y la irracionalidad, aspectos que desde la teoría de la complejidad introducen una integración fundamental entre autos y Oikos, reciprocidad que en su traducción literal involucra la auto-reproducción de los dominios de sí mismo (Oikos: ambientes, cosmos, hábitat) importantes para comprender a nivel individual y colectivo la relación dialógica, reflexiva y recursiva entre el ser vivo y su ecosistema, es decir entre los sistemas complejos. Así el "autos" del aprendizaje ecológico se orienta hacia la autoproducción de saberes 
e interrelaciones entre especies (producción de sí mismo) y funciona a través de procesos complejos de apertura (intercambio de información y recursos), cierre/ clausura organizacional (identidad, independencia y legitimidad de sus procesos y transformaciones internas) y del principio de recursión organizativa (imbricación de lo emergente y reactualización-reorganización del sistema), condiciones propias de un bucle inter-retro-activo en que la relación pedagógica autos-oikos no anula los elementos discursivos en juego sino que integra incluso lo adverso, aquello que es su contrariedad anulativa. En este reconocimiento recíproco autos y Oikos son irreductibles el uno al otro e "indisociables en su mutua interdependencia" (Carrizo, Espina \& Klein, 2004, p. 51).

En el caso de la destrucción y contaminación de los ecosistemas del planeta las causas y consecuencias guardan relación con las acciones y abusos en la explotación de sus recursos, el cuidado inadecuado de las fuentes de agua, el crecimiento y expansión industrial desmesurado, la ciencia y la tecnología empleada para actuar en contra de la vida y a favor de la muerte (Delgado et al, 2005), condiciones que afectan la continuidad recursiva-organizacional de todas las especies y formas de vida. Para Maturana (2002) "todo lo que les pasa a los seres vivos tiene que ver con ellos y no con otra cosa. Son sistemas autónomos, en los que su autonomía se da en su autorreferencia" (p. 29) así cada sistema expresa la coherencia de su funcionamiento a través de sus procesos organizadores y creadores que paradojalmente están conectados por fuerzas antagónicas pero complementarias. Por tanto la acción pedagógica ecologizante da cuenta de una acción anti-ecológica que se reproduce solapadamente en los sistemas educativos, a partir de la cual surge la necesidad de implementar acciones de cambio inmediato desde los escenarios educativos. La propuesta cosmovisiva de plantar semillas de incertidumbre hace que cada momento de interacción con el medio ambiente propicie la solidaridad, cuidado y reparación del mismo, suscitando creaciones, constreñimientos, emergencias y auto-eco-reorganizaciones del sistema movilizadas por diversas tramas de eventos que son en sí mismos Hologramáticos -parte y todo, devenir, concurrencia y complementariedad-.

Desde un escenario complicado el pensamiento reductor invita a la determinación del fenómeno social por efecto de operaciones lógicas rectoras pseudo-inamovibles, mientras desde pensamiento ecologizante se incluyen estos procesos y se proponen modelos pedagógicos multidiversos que incluyan la incertidumbre, el asombro la creatividad y la aceptación de la diversidad en la unidad y viceversa, así las "incertidumbres semilla" se constituyen en el principio recursivo o de recursión organizativa que incorpora la producción y la auto-organización de saberes respecto al medio ambiente y los ecosistemas. La pedagogía ecologizante crea escenarios de encuentro en los que toda acción educativa en marcha es un producto y sus efectos constituyen acciones productoras y causantes de aquello que los produce (CDI, 2012a), para el caso del pensamiento ecologizante aquello generado en el proceso de bucle es una nueva conciencia ecológica. Humberto Maturana (2002) indica que "una cultura es una red de coordinaciones de emociones y acciones en el lenguaje que configura un modo particular de entrelazamiento del actuar y el emocionar de las personas que la viven" (p. 138) es decir una red cerrada de conversaciones, la 
cual define y constituye todo quehacer de una comunidad humana pero no limita sus acciones al control y lo predecible. Por ello la pedagogía ecologizante opera a través de una compleja red y de puentes socio-culturales comunicantes entre diversas disciplinas y experiencias, que puede reproducirse en, a través y más allá del saber de las ciencias y de las instituciones sociales, y tiene como objetivo el expandir-difundir-(de)construir los conocimientos a todos los colectivos humanos.

La educación propuesta es de tipo ecosistémica por lo que sus modelos y posturas deben estar en continuo cambio a razón de las constantes acciones, retroacciones e inter-retro-acciones entre sus componentes (personas, grupos, redes, instituciones, saberes, experiencias etc.), aspecto manifiesto en su operar como sistema abierto al tiempo que como red cerrada de cambios de relaciones de actividad (Maturana, et al, 2002), lo cual esta mediado por todo aquello que el observador comprende como interacciones recurrentes con su ecosistema. Las incertidumbres semilla son propuestas de reforma de la cosmovisión ecológica-planetaria en los adultos, pero son también puntos educativos-motivacionales en los niños y niñas, quienes al vivir en la conciliación recíproca con el medio ambiente, se conectan de forma natural y espontánea con el cosmos que está en ellos a través del asombro por descubrir lo emergente de un mundo perteneciente a todos. 


\section{Referencias bibliográficas.}

Bateson, G (1999). Pasos hacia una ecología de la mente. España: Editorial Lohlé-Lumen.

Bleger, J. (1974). Psicologia de la conducta. Cap. XIII Conductas Defensivas. Editorial Paidós.

Carrizo, L. Espina, M \& Klein, J. (2004). Gestión de las transformaciones sociales. (MOST). Documento de debate $\mathrm{N}^{\circ}$ 70. UNESCO, Organización de las Naciones Unidas para la Educación, la Ciencia y la Cultura.

Chavez, A. (2005). "La bioética como nuevo saber ético. Hacia una precisión de su verdadero estatus" en Bioética y medio ambiente. Selección, Compilación y Edición Científica: Dr.C. Carlos J. Delgado Díaz. La Habana.

Colectivo docente internacional. (2012). [CDI]. Complejidad y pensamiento científico. Módulo II. Maestría en pensamiento complejo. La construcción de vias distintas.

Colectivo docente internacional. (2012a). [CDI]. Glosario complejidad y pensamiento científico. La construcción de vias distintas.

Colectivo docente internacional. (2012b). [CDI]. Complemento del módulo VI: Bioética y ambientalismo. Maestría en pensamiento complejo. La construcción de vias distintas.

Delgado, C.J. et al. (2005). Bioética y medio ambiente. Varios autores. Selección, Compilación y Edición Científica: Dr.C. Carlos J. Delgado Díaz. La Habana.

Delgado, C.J. (2005). Hacia un nuevo saber. La Bioética en la revolución contemporánea del saber. La Habana-Cuba.

Fiorini, H. (1987). Las funciones yoicas en el proceso terapéutico. En Teoría y técnica en Psicoterapias, Buenos Aires, Editorial Nueva Visión.

Habermas, J. (1985). El discurso filosófico de la modernidad. Editorial Taurus, Barcelona.

Habermas, J. (1989). Conocimiento e interés. Editorial Taurus, Barcelona.

Luhmann, N. (1991). La clausura operacional de los sistemas psíquicos y sociales. Edición: 1992 España. Gedisa. En "El final de los grandes proyectos. Compiladores: Fischer, Schweizer y Retzer. 
Lumelsky N. y Cols. (2001). "Los límites del crecimiento y la ética del consumo". Temas para el debate. $\mathrm{N}^{\circ}$. 76, 3. Recuperado de http://www.cubaenergia. $\mathrm{cu} /$ genero/ambiente/a23.pdf

Maturana, H. (2002). El sentido de lo humano. Santiago de Chile, Editorial: Dolmen Ediciones.

Mayor, F. (1999). Texto introductorio de la obra de Edgar Morin: "Los siete saberes necesarios para la educación de futuro". UNESCO. Organización de las naciones unidas para la educación, la ciencia y la cultura.

Morin, E. (1984). Ciencia con consciencia. Anthropos, Barcelona.

Morín, E. (1996). Pensar el Mediterráneo. Mediterranizar el Mediterráneo.

Morín, E. (1996a). El pensamiento ecologizante. Gazeta de Antropología $\mathrm{N}^{\circ} 12$, 1996 Texto 12-01 recuperado de http://www.ugr.es/ pwlac/G12_01Edgar_ Morin.html.

Morín, E. (1999). Los siete saberes necesarios para la educación a futuro. UNESCO. Organización de las naciones unidas para la educación, la ciencia y la cultura.

Morin, E. (1966). El pensamiento ecologizado. Gazeta de Antropología, Nº 12, 1966.

Morín, E. (2002). El método, la vida de la vida, Madrid, Cátedra, 2002.

Morín, E. (2003). Globalización: civilización y barbarie. Copyright Clarín y Le Monde. 2003. Traducción de Cristina Sardoy.

Morín. E. (2007). Artículo: "Las noches están preñadas y nadie conoce el día que nacerá". "Les nuits sont enceintes et nul ne connaît le jour qui naîtra. Le Monde - Artículo publicado en la edición del 09.01.11 - Paris.

Potter, V. (1998). "Bioética Puente, Bioética Global, Bioética Profunda”, Cuadernos del Programa Regional de Bioética, No.7.

Revista TIME. (2010). Top 10 Environmental Disasters. Disponible en http://content.time.com/time/specials / packages / article/0,28804,1986457_1986501_1986443,00.html.

Romero, C. (2003). Paradigma de la complejidad, modelos científicos y conocimiento educativo. Universidad de Huelva. Revista Ágora, 6(6), 1-10, recuperado de http:/ / www.uhu.es/agora/version01/digital/numeros/06/06-articulos / monografico/pdf_6/clara_romero.pdf . 
VEOVERDE. (Mayo de 2010). En prensa: Blogg acerca de "Los 10 peores DESASTRES Ambientales de la Historia". Consultado el 24 de marzo de 2014. Recuperado de http://www.veoverde.com/2010/05/los-10-peoresdesastres-ambientales-de-la-historia/ 